\begin{tabular}{c} 
Volume and Issues Obtainable at Center for Sustainability Research and Consultancy \\
Journal of Business and Social Review in Emerging Economies \\
ISSN: 2519-089X (E): 2519-0326 \\
Volume 3: Issue 2December 2017 \\
CSRᄃ \\
Journal homepage: $\underline{\text { www.publishing.globalcsrc.org/jbsee }}$ \\
\hline
\end{tabular}

\title{
Non-Monetary Incentives to Improve Job Performance at Property Company in Penang Malaysia
}

\author{
${ }^{1}$ Nur FatinNazierah Abu Bakar, ${ }^{2}$ Bidayatul Akmal Mustafa Kamil, \\ ${ }^{3}$ Siti Norasyikin Abdul Hamid, ${ }^{4}$ Shamsul Huda Abd Rani
}

\author{
${ }^{1}$ Researcher, School of Business Management, Universiti Utara Malaysia, \\ ${ }^{2}$ Lecturer, School of Business Management, Universiti Utara Malaysia, bidayatul@uum.edu.my \\ ${ }^{3}$ Lecturer, School of Business Management, Universiti Utara Malaysia, norasyikin@uum.edu.my \\ ${ }^{4}$ Lecturer, School of Business Management, Universiti Utara Malaysia, shuda@uum.edu.my
}

\begin{abstract}
ARTICLEDETAILS
History

Revised format: Nov 2017

AvailableOnline: Dec 2017
\end{abstract}

\section{Keywords \\ Non-monetary Incentives, Job Performance, \\ Flexible Working Schedules, \\ Recognition, \\ Career Development}

JEL Classification:

J62, J69, O15

\begin{abstract}
Purpose: The purpose of this study is to examine the relationship of nonmonetary incentives such as flexible working schedules, recognition and career development on job performance.

Design/Methodology/Approach: The respondents of the study were among employees who work with property company in Penang. In this study, the quantitative method was implemented. In assessing the relationship between the variables, a total of 91 questionnaires were analyzed using descriptive and inferential data analysis technique. The method of analysis used in this study includes reliability test, Pearson correlation and multiple regression.

Findings:The findings of this research reveal that flexible working schedules, recognition and career development has significant relationship on employees' job performance.

Implications/Originality/Value:The findings of the study can be applied by the management of property company in their effort to enhance job performance of their employees by considering the determinant factors involved in this study, particularly in enhancing the non-monetary incentives. Moreover, this study may help in improving employees' job performance and thereby gaining higher rewards and benefits to them. Consequently, the research provides guidance how non-monetary incentives works or give positive result in such a way it gives employees and organization enough satisfaction.
\end{abstract}

(C) 2017 The authors, under a Creative Commons AttributionNonCommercial-ShareAlike 4.0

Corresponding author's email address: bidayatul@uum.edu.my

Recommended citation:Fatin,N.N., Akmal,B.M.,K, Norasyikin, S.A.H.\& Huda.S.A.R., (2017). Non-Monetary Incentives to Improve Job Performance at Property Company in Penang.Journal of Business and Social Review in Emerging Economies, 3(2) 245-252. DOI: https://doi.org/10.26710/jbsee.v3i2.89

\section{Introduction}

Employee performance is a fundamental component which helps in organizational development and sustainability, specifically those who are affected by the reward system employed in an organization (Ngulube, 2003). The world business environment has experienced a huge transformation for the last few decades. In terms of communications, competition and economics, people can see that the world has become smaller thus affect the way successful organizations do business and they manage their employees. This change or transformation has affected the private sector altogether and is affecting the 
public organizations too, both in direct and indirect ways. More global organizations are becoming more approachable to their customers, decreasing costs, and improving quality (Erbasi, 2012).

In the organization, the role of monetary and non-monetary reward system is to motivate the employees to invest their effort and skills as maximum as possible of their potential to contribute to achieve the organizational goals. Employees are able to apply their creativity and innovation ability when the reward system is implemented in the organization. Employees are also able to take on greater responsibility and demonstrate commitment with their tasks execution, bringing about higher achievement and improved working performance with the reward system implemented in the organization. When the combination of both monetary and non-monetary forms of stimulation is accomplished through full engagement of employees the result will indicate a higher degree of output and quality through increased efficiency, productivity, and effectiveness.

This study focuses on the important of non-monetary incentives to employees on job performance among employees at one Property Company in Penang. It is highlighted that the need for recognition, selfrespect, growth, meaningful work, social activities is important as monetary incentives in increasing the employees' job performance. There are many contemporary research studies supporting the effectiveness of non-monetary incentives as a motivating tool in improving job performance the private sector organizations. However, there is insufficient study regarding its use in property industry. Consequently, this study attempts to highlight on the issue and explore the effect of non-monetary incentives to job performance in Malaysia Company.

The aim of this study was to identify factors that influence the job performance in the organization since there are several factors related to job performance in the organizations. The dependent variable is job performance and the independent variables are flexible working schedule, recognition and career developmentThe purpose of this research is to examine the relationship between all independent variables (IV) and dependent (DV). The specific objectives are:

1. To determine the relationship between flexible working schedules and job performance

2. To identify the relationship between recognition and job performance

3. To examine the relationship between career development and job performance

\section{Literature Review}

Incentives have been seen to be an important mechanism in employee job performance in the organization. Employees whom received a reward from the organization feel that he or she is being appreciated by the employer for their job performance. Employees are encouraged to work extra hard since their performance is being seriously considered by the employers. Their career development and self-development are also taken into consideration and taken care by the organization.

The term "incentives" and "rewards" are used widely in organizations and it configures the same meaning among these two terms. Incentives can be defined as any medium that boosts employees or team of employees to accomplish better results beyond expectations. Incentives can be divided into two main categories which are monetary and non-monetary incentives. In monetary incentives, it includes direct payment of cash meanwhile non-monetary can be in the form of employee promotion to a higher position, flexible working hours, autonomy and getting involve in decision making. Organizations that have a balanced incentive program will likely motivate employees and as a result lead to improved performance (Petrescu\& Simon, 2008).

\subsection{Flexible Working Schedule}

According to Burns and McKinnon (1993), flexible working schedules have a positive impact on employee performance. First, they lead to improved morale. Employees that were given flexible working arrangements feel that they have a better work-life balance than those who are bound to an office Monday through Friday from 8 am to 5 pm with just one-hour lunch break. When employees feel good about their jobs, they create a good working environment for others and thus increase the employee's morale. 
Furthermore, a flexible working schedule can make employees feel excited to go to work and in a good spirit. Moreover, a flexible working schedule helps employees in terms of their health condition. This is because creating high-quality self-confidence helps to maintain stress at a manageable level. As a result, employees become blissful and healthier. On the other hand, employees who work at companies where morale is considered a problem sometimes have difficulties in health like depression and substance-abuse issues (Ballentine, McKenzie, Wipocki\&Kepner, 2007).

\subsection{Recognition}

Recognition is considered as a powerful motivator that establishes a positive work culture (Reddy, 2000). Recognition is important as it serves to encourage workers to be confident and to believe in themselves in order to deliver quality products and services, and to generate loyalty to the organization. Some scholars state that the use of non-monetary rewards is often ignored by organizations. Non-monetary rewards tend to have a longer-lasting effect and can be used more frequently than monetary rewards. These types of rewards can be given at anytime and anywhere on-the-spot when an employee is doing a good job, which reinforces good performance, recognition to the employee when peers are present, and encourages everyone to strive for excellent.

These types of rewards are internal since they cater the internal needs of employees such as self-esteem, recognition and accomplishment. So, whether or not an employee's internal needs are being met significantly give impacts to individual job satisfaction and motivation (Burns \& McKinnon, 1993). There are other ways of rewarding that focuses on the appreciation towards the employees, which includes the praise that employees get from management, opportunity to run important tasks or projects, and even the leadership consideration (Dewhurst, Guthridge \& Mohr, 2010). Recognition can be separated into monetary and non-monetary incentives such as crediting, encouraging and appreciating individuals and groups who give full effort to the success of the organization. In addition, recognition also give a feeling of valued as part of the team in the organization.

\subsection{Career Development}

Career revolves around three basic themes that include advancement in career position, source of stability within single occupational field and evolving sequence of a person's work experience. Career development is the series of activities or the on-going or lifelong process in developing an individual's career. In addition, managing one's career in an intra-organizational or inter-organizational scenario usually refers to career development. Frequently, career development involves training new skills, moving to higher job responsibilities, career change within the same organization, moving to a different organization or starting their own business. According to Holbeche (1999), career development has always remained as a significant concern for employees in organizations whenever they have time to manage it properly.

According to Dewhurst, Guthridge \& Mohr (2010), it was claimed there are other methods that can offer rewards to employees, particularly employees whose focus is not only on compensations that are moneyvalued oriented. For example, one of the most crucial is opportunities for participating in organization projects, leadership attentions and trainings as well as receiving guidance about career.

Moreover, career development as a non-monetary reward is applied to employee's job performance and it also useful in improving their morale towards day-to-day job responsibilities in the organizations. It is also as a way of rewarding them for good work and being considered essential in rewarding high achievements within an organization for employees and caring for customer's needs, which both are not dependent on achieving a target that is already pre-determined in the organizational goals (Rose, 1998). Also, career development as a form of incentive applied in organizations has mostly been considered as an effective method of employee compensation which in result attracts and leads to workforce maintenance. 


\section{Methodology}

Based on the sample frame by Krejcie and Morgan (1970) from the total population of 110, a total of 86 respondents were the sample size selected to complete the survey.The researchers distributed 100 sets of questionnaires to the property company, and 91 sets responded. Likert Scales was employed in these sections, with the purpose of evaluating the respondent's perspectives on each given statements. It ranged from strongly disagree (1), disagree (2), neither agree nor disagree (3), agree (4), strongly agree (5). This study used statistical analysis techniques with the assistance from the Statistical Package for Social Sciences (SPSS) version 23 software to analyze the data.

\section{Findings and Discussions}

Result of the analysis shows that all independent variables have a significant positive correlation with the dependent variable $(\mathrm{p}<0.01)$. Moreover, all independent variables are observed to have strong relationship with job performance as the $r$ values are above 0.50 . Individually, there is a significant relationship between flexible working schedules and job performance $(\mathrm{r}=0.659, \mathrm{p}<0.01)$. The correlation value also indicates positive relationships between flexible working schedules and job performance. Similarly, there is a significant relationship between recognition $(r=0.633, p<0.01)$. It also indicates positive relationship between recognition and job performance. In addition, career development also shows a positive significant relationship with job performance $(r=0.542, \mathrm{p}<0.01)$.

Table 1.0

Pearson Correlation Coefficient

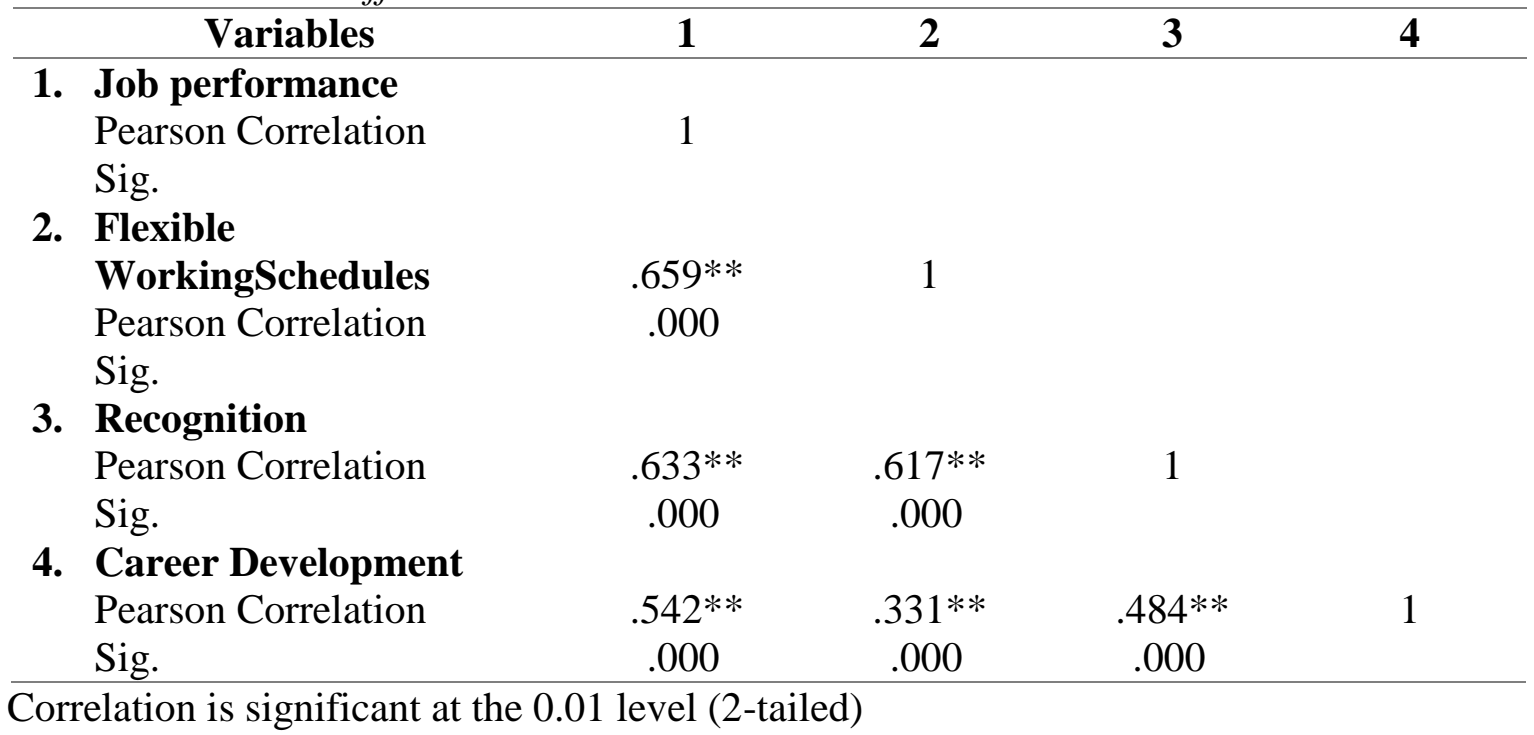

Multiple regression analysis is the analysis that used to test and interpreted the effect of one or more independent variables on a dependent variable. Regression allows researchers to understand how much of the variance in the dependent variable is interpreted by a set of independent variables. The three determinants (flexible working schedules, recognition and career development) explain $58.2 \%\left(\mathrm{R}^{2}=\right.$ 0.582) of the variance in job performance. It indicated that job performance is explained by flexible working schedules, recognition and career development. Meanwhile, the rest of $41.8 \%$ is explained by the other variables.

Table 2.0

Model Summary and Coefficient

\begin{tabular}{lccc}
\hline Variables & $\begin{array}{c}\text { Standardized } \\
\text { Coefficients }\end{array}$ & T & Sig. \\
\cline { 2 - 3 } & Beta & & \\
\hline
\end{tabular}




\begin{tabular}{lccc}
\hline (Constant) & & 2.451 & .016 \\
Flexible Working Schedule & .418 & 4.748 & .000 \\
Recognition & .235 & 2.474 & .015 \\
Career Development & .290 & 3.658 & .000 \\
R-Square & & .582 & \\
Adjusted R Square & .568 & \\
Sig. F Change & .000 & \\
\hline
\end{tabular}

The first research objective deals with the relationship between flexible working schedules and job performance. Many studies have revealed that flexible working schedules have a significant influence on job performance. Results from the Pearson correlation test indicate a positive relationship between flexible working schedules and job performance. The relationship is also strong where the $r$ value is 0.659. This study has therefore proved that positive flexible working schedules may boost the job performance of employee in organization. The largest beta coefficient is 0.418 which is for flexible working schedules. This carry the meaning of flexible working schedules variable makes the strongest contribution in explaining job performance. It suggests that one standard deviation increase in flexible working schedules is followed by 0.418 standard deviation increase in job performance. This means that flexible working schedules significantly influence job performance. Thus, it support the hypothesis one (H1) "There is a significant relationship between flexible working schedule and job performance". The findings were in accordance to Latham's (1993) who declared that flexible working schedules leads to improved productivity, and it plays a major role in promoting the satisfaction of employees to perform even better in their job, which in turn leading to improved organizational performance.

The second research objective concerns with the relationship between recognition and job performance. Many studies that were conducted indicated that recognition has a significant influence on job performance. The results from the Pearson correlation test demonstrated a positive relationship between recognition and job performance. The relationship is also strong where the $r$ value is 0.633 . The second highest beta value falls on career development with 0.290 values. This meaning that career development variable makes a strong contribution in explaining the job performance. It suggests that one standard deviation increase in career development is followed by 0.290 standard deviation increase in job performance.This means that career development significantly influence job performance. Thus, it support the hypothesis two (H2) "There is a significant relationship between career development and job performance". This study has therefore proved that positive recognition rewards may boost the job performance of employee in organization. The result of this is found to be consistent with findings from previous researches, where it was indicated that the uses of recognition reward affect job performance in either positive or negative way. For example, a research conducted by Nelson and Quick (2004) proved that praise and recognition are considered as the most efficient intrinsic reward which rises the employee job performance.

The third research objective deals with the relationship between career development and job performance. From the results obtained in the previous chapter, it appeared that career development also has a positive significant influence on job performance but has the lowest correlation value among tested variables; flexible working schedules and recognition. The results from the Pearson correlation test suggest a positive relationship between career development and job performance. The relationship is also strong where the $r$ value is 0.542 . This study has therefore proved that positive career development rewards may boost the job performance of employee in organization. The standardized coefficient beta for recognition is 0.235 in values. This meaning that variable recognition makes the least contribution in explaining the job performance. It suggests that one standard deviation increase in recognition is followed by 0.235 standard deviation increase in job performance. This means that recognition significantly influence job performance. Thus, it support the hypothesis three (H3) "There is a significant relationship between recognition and job performance". The finding was in accordance to Robert (2011) study that showed 
respondent at Altamonte Springs Police Department agreed that career development enhance employee performance and have a positive impact on an organization's overall effectiveness. Similarly, previous study by Ngatia (2014) also proved a high significant relationship between career development and job performance. 69 per cent of respondents' response indicated that high level of organizational effectiveness is achieved when organizations adopt career development in boosting employee performance.

\section{Conclusion}

This study investigated the non-monetary incentives factor that could influence job performance of employees at a property company in Penang. The factors are flexible working schedules, recognition and career development. Through the result, it is indicated that all three variables tested have positive relationship and significant value on job performance. This research can be helpful for employers in the private organization especially in property sector. They can design effective incentives package to maintain and retain their capable employees thus improving the job performance. Management can also improve the use of effective non-monetary incentives including recognition system in the feedback process of their performance management system in order to motivate their employees. Since job performance is a function to enhance non-monetary incentives, it is hoped that this study will provide significant information that will be of great value to this property company. This is because this research provides fresh insights as to enhance the employee performance through having the right non-monetary incentives.

\section{Limitation}

Lastly, only three variables were identified to study the non-monetary incentives to job performances which are flexible working schedules, recognition and career development. However, there were also many other factors that is related to the job performance of the employees. Thus, selecting only three factors is considered a limitation. Moreover, future study should expand the scope by including others factor that may influence job performance. Despite the limitations, the findings of this study still provide a platform for future investigation to improve the current awareness about which factors are significant in relation to job performance.

\section{Recommendation for Future Research}

Even though various studies in the past assessed the situation of non-monetary rewards use and status most organizations today in some characteristics, there has been lack of detailed study that has been conducted on how flexible working schedules, recognition and career development as non-monetary incentives influence employee job performance in property sector. Therefore, it is essentialto observe, update and document the situation whenever new data are available as this would allow the identification of improvements by conducting a study of the influence of non-monetary incentives on employee performance in order to reduce the research gap in this area of study.

\section{References}

Ballentine, A. McKenzie, N.Wipocki, A., \&Kepner, K. (2007).The Role of Monetary and Non-Monetary Incentives in the Workplace As Influenced By Career Stage. Retrieved from edis.ifas.ufl.edu

Burns, W.J. and McKinnon, S.M. (1993). Information and Managers: a Field Study. Journal of Management Accounting Research, 5, 84-123.

Dewhurst, M., Guthridge, M., Mohr, E., (2010). Motivating people: getting beyond money, Business Source Complete.

Erbasi, A. (2012). The Effect of Financial and Non-financial Incentives on Job Satisfaction: An Examination of Food Chain premises in Turkey. International Business Research, Vol. 5, No. 10.

Holbeche, Linda. (1999). Aligning Human Resource and Business Strategies. Butterworth Heinemann. Latham, G. (1993). Increasing productivity through performance appraisal. Addison Wesley.

Nelson, D.L. and Quick, J.C. (2004), Organizational Behaviour: Foundation, Realities and Challenges 
(4th ed.), Australia: Thomson South-Western.

Ngulube P. (2003). Preservation and Access to Public Records and Archives in South Africa.PHD Thesis.Pietermaritzburg: University of Natal.

Petrescu, A. and Simon, R. (2008).Human Resources Management Practices and Worker's Job Satisfaction.International Journal of Manpower, 29(7): 651- 667.

Reddy, V. L. (2000, February).Mantras on Motivation.Retrieved from nfa.usfa.fema.gov/pdf/efop/efo35676.on 12 March 2017.

Robert C. Merchant, Jr (2011). The Role of Career Development in Improving Organizational Effectiveness and Employee Development.

Rose, M. (1998). Performance-Related Pay In Schools: An Assessment of the Green Paper, NUT: London. www.hinduonnet.com/jobs/0002/05160051.htm. 
